\title{
Employee Involvement in Decision-Making: A Case at One Univesity of Technology in South Africa
}

\author{
Lawrence Kok \\ Vaal University of Technology \\ lawkoki@gmail.com \\ Malefane Johannes Lebusa \\ Vaal University of Technology \\ johannesl@vut.ac.za \\ Pierre Joubert \\ Vaal University of Technology \\ pierre@vut.ac.za
}

Doi:10.5901/mjss.2014.v5n27p423

\begin{abstract}
The higher education landscape in South Africa is dynamic and one of the most rapidly changing environments, which is undergoing fundamental metamorphosis. The higher education institutions (HEls) are facing, among other challenges, the alterations in government funding and globalisation of higher education which bring with them new competitors. It is in this sense that this study focuses on the involvement of operational employees in decision-making processes. This study sets out to explore the employee perceptions of them being involved in decision-making with an emphasis on the cascading of responsibility and accountability for power, information, knowledge and rewards to lower levels within their institution. A quantitative study was conducted with 410 randomly selected employees within one University of Technology in South Africa. The overall perception of employees with regard to their involvement in decision making indicated that there is a lack of them being involved in decision making processes.
\end{abstract}

Keywords: Involvement, decision making, Higher Education Institutions employees,

\section{Introduction and Background to the Study}

The higher education landscape in South Africa is dynamic and one of the most rapidly changing environments which is undergoing fundamental metamorphosis (Wessels, 2002:189). The higher education institutions (HEIs) are facing, among other challenges, the alterations in government funding and globalisation of higher education which bring with them new competitors. The traditional focus of applied and vocational education is shifting, with Universities of Technology (UoTs) becoming more academic and traditional universities becoming more applied in their educational offerings (Pityana, 2004:1).In this period of rapid intellectual change, the need for a different type of institution which taps in the talents and skills of its employees at any level of employment has become self-evident. It is in this sense that this study focuses on the involvement of operational employees in decision-making processes (Vance, 2006:57).

Within South African organisations, including HEls, it appears that the traditional approaches to human resource management that had been conceived in cultures emphasising command and control, are giving way to new approaches that are characterised by greater employee commitment, cooperation and communication (Grobler, Warnich, Carrel, Elbert \& Hatfield 2011:4). The ultimate net outcome is that HEls are becoming more proactive in dealing with their employees as the latter have been described as being one of the most important resources, if not indeed the key resource, of institutional success. Such institutions should therefore make a long-term commitment to developing employees in order to render them even more valuable, and managers should arrange work so that the personal goals of employees and those of the institution are in support of one another (Ang, 2002:194).

According to Echols and Neck (1998:38), HEls that do not keep up with the fast pace of changes may go the way of the dinosaur hence, the need for them to evolve. One of the major qualities of institutions of higher learning is to be 
responsive and relevant to the needs of the environment (du Pre 2005).Cummings and Worley (2008) further emphasise the importance of change in these institutions by indicating that the pace of global, economic, and technological developments renders change an inevitable feature of organisational life.

Employee involvement in this study is defined by Schultz, Van der Walt and Bezuidenhout (2011:55) as creating an environment in which employees have an impact on decisions and actions that affect their jobs. It constitutes a concerted effort by employers to find participative ways in which to manage their staff by investing in human capital. There is a body of evidence to prove that employee involvement in decision-making is a key driver of organisational performance. A casual observation suggests that much of the appeal to organisational management is driven by claims that employee involvement drives bottom-line results (Macey \& Schneider 2008:198).

The assumption of this study is that employees who are best organised in an organisation and involved in decisionmaking will harness their full potential. They will perform better than others, take fewer sick leave days and are less likely to leave (Edwards,2007:1). They will be empowered to make decisions and solve problems appropriate to their level in the organisation. HEl's are challenged to embrace human resource perspectives which hold that employees should be treated fairly and with respect, and that cooperation with management should be encouraged (Ang,2002:192). This climate would include the sharing of decision-making so that employees have a say in decisions that influence them (Wanberg \& Banas , 2000:139).

\section{Literature Review}

\subsection{The nature of employee involvement in decision-making}

In recent years there has been a renewed interest in various forms of employee involvement and participation (Frost, 2000: 268) such involvement has retained its place on the management agenda. It is commonly argued that the renewed interest in this type of involvement and participation in decision-making, apparent in management and industrial relations literature is part of a number of organisational changes being trialled by organisations in response to increasing competitive pressures arising in both local and international markets. It can be seen as a key component of best practice in human resource management (Pfeffer, 1998:74) or high commitment management (Wood, 1999:22).

Employee involvement is neither the goal nor a tool, as practised in many organisations. Rather, it is a management and leadership philosophy regarding how employees are most enabled to contribute to continuous improvement and on-going success of their work. It is a process which allows employees to exert some influence over their work and the conditions under which they work (Heller, Pusic, Strauss, \& Wilpert, 1998:628). Employee involvement is a means to examine the operation of democratisation in the organisation, which not only diminishes the obstacles to the operating system, but is also the way to gain a common consensus and pursue the goal of providing benefits to most people (Lin, 2006:69). It is special form of delegation in which the subordinate gain greater control and greater freedom of choice with respect to bringing the communication gap between the management and the workers (William, 2008:25). The main aim of employee involvement reflect a management agenda concerned with increasing understanding and commitment from employees and securing an enhanced contribution to the organisation.

\subsection{Decision-making}

At the centre of the definition of the concepts participation, empowerment and employee involvement is the concept decision-making (Knudsen, 1995:54). The broader term decision-making is defined by Stoner, Freeman and Gilbert $(1995: 239)$ as a process of identifying and selecting a course of action to deal with a specific problem or take advantage of an opportunity. It is a process by which managers respond to the opportunities and threats that confront them, by analysing the options and making determinations, or decisions, about specific organisational goals and courses of action (Jones, George \& Hill:196). According to Hellriegel, Jackson and Slocum (2005: 208) it includes, defining problems, gathering information, generating alternatives and choosing a course of action.

\subsection{The advantages of employee involvement in decision-making}

The fierce, competitive environment currently existing throughout the globe is forcing many organisations to transform themselves to a new paradigm for manufacturing, including employee involvement. Scholars and practitioners (Jones, Kalmi \& Kauhanen, 2010:18) believed involvement programs are a necessary component to success in today's competitive environment. If this is true, the questions arise as to why only one-third of organisations report having 
involvement programs, and what factors account for the low $10 \%$ involvement rate of employees.

According to Noah (2008:36) for an employee involvement process to be effective, three things need to be present:

- Employees need to be given the authority to participate in substantive decisions

- Employees need to have the appropriate decision-making skills

- Incentives to participate (whether implicit or explicit) must be present

Employee involvement exists in organisations that intentionally establish work cultures, systems and processes to encourage and make use of employee input and feedback. Involving employees more in decision making has become increasingly common in early 21st century organisations as companies see benefits in keeping employees at all levels actively engaged in core activities. Direct involvement of employees help an organisation fulfil its mission and meet its objectives by allowing employees applying their own ideas, expertise, and efforts towards solving problems and making decisions. It is a range of processes designed to engage the support, understanding and optimum contribution of all employees in an organisation and their commitment to its objectives. Employee involvement in decision-making has resulted in successful value creation in many organisations.

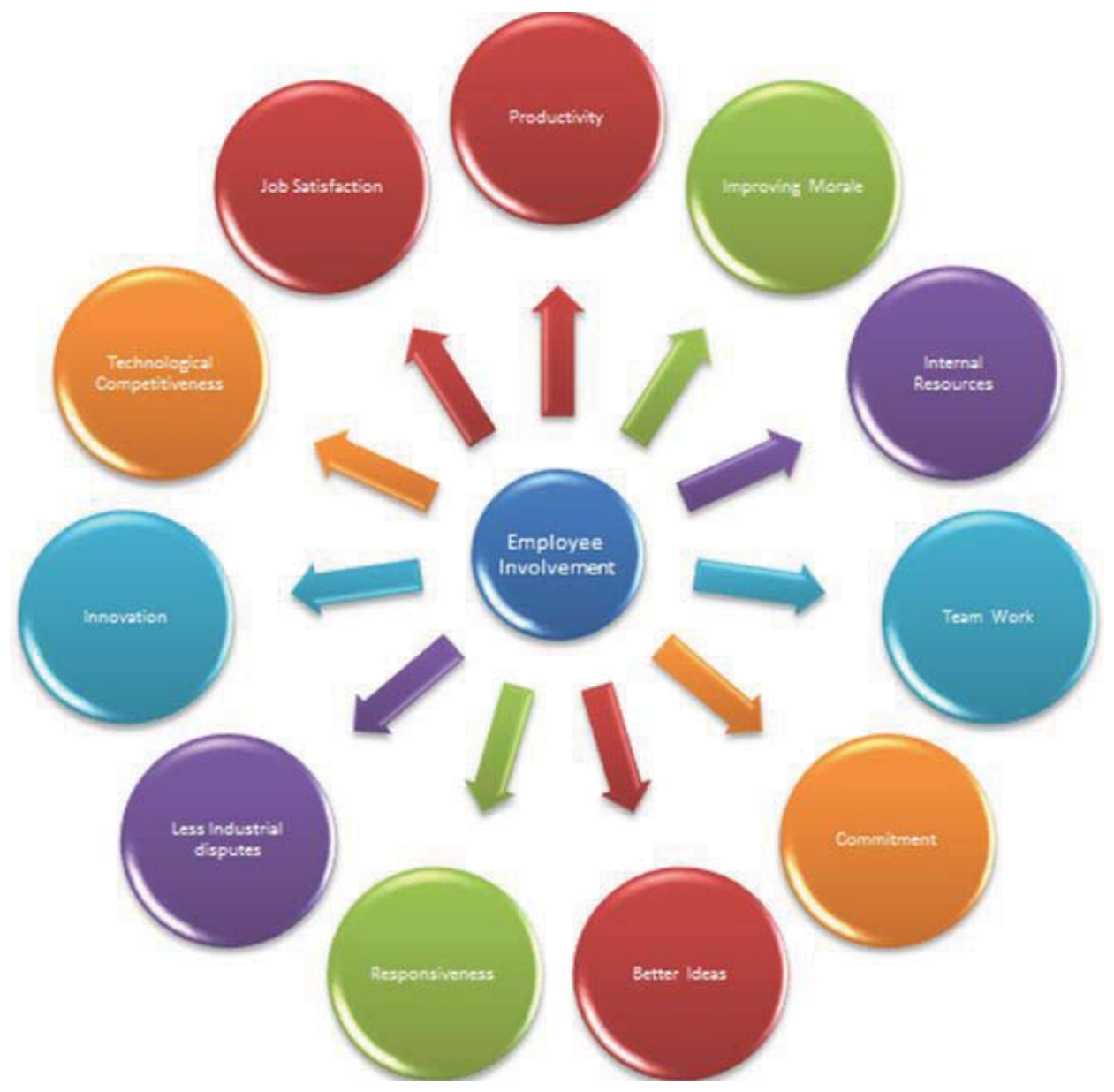

Figure 1: Employee involvement advantages model

Adopted from Bhatti \& Qureshi (2007)

Ahmed (2013: 22) shares the following positive responses of employees in the involvement process:

- a positive attitude towards, and pride in, the organisation

- belief in the organisation's products/services

- a perception that the organisation enables the employee to perform well

- a willingness to behave altruistically and be a good team player

- an understanding of the bigger picture and a willingness to go beyond the requirements of the job. 
This study sets out to explore the employee perceptions of their involvement in decision making with the emphasis being placed on the cascading of responsibility and accountability for power, information, knowledge and rewards to lower levels within their institution.

\section{Research Methodology}

\subsection{Research sample}

The study population was drawn from one University of Technology and comprised of both academic and non-academic staff who do not hold management positions. The sample was drawn from this university of technology and included academics, administrators as well as service workers $(\mathrm{N}=1400)$. A random sample of $(\mathrm{n}=600)$ was selected for the study.

\subsection{Method of data collection}

Information gathered from the literature study was used to develop and design a questionnaire to gather information from employees with regard to their involvement in decision-making at the institution. The study thus employed quantitative methodology for data collection, analysis, its organisation and interpretation. (De Vos, Strydom, Fouche\&Delport 2002).

\subsection{Measuring instrument}

According to Vockel and Asher (1995:192), quantitative research involves description and data-collection processes, research designs and statistical procedures and includes among other, questionnaires. To this end, this study made use of a questionnaire as the quantitative research instrument because this facilitatedthe quantification of employee perceptions regarding their involvement in decision-making at their institution. The questionnaire consisted of 2 sections. Items in section A related to the biographical information of the respondents. The information was essential as it contributed to the researcher's understanding of the responses and the possible reasons for them (Boyce 2002:39). Questions in this section related to information about respondents' gender, work experience, academic qualifications, job designations and job levels.Questions in section B were categorised according to the dimensions identified from the literature study namely reward, power, information and knowledge. Respondents were asked to indicate on a 4point Likert scale the degree to which they viewed items in their present work situation as far as their involvement in decisionmaking was concerned, that is, strongly agree, agree, disagree and strongly disagree.

\section{Results and Discussion}

Four hundred and eight usable questionnaires were returned, representing a response rate of $68 \%$. The employee involvement dimensions yielded high Cronbach Alpha coefficients, which is an indication of high reliability, as illustrated in table 1.

Table 1: Questionnaire reliability

\begin{tabular}{|c|c|}
\hline Dimension & Cronbach Alpha \\
\hline Power & 0.893 \\
\hline Information & 0.883 \\
\hline Knowledge & 0.843 \\
\hline Reward & 0.896 \\
\hline
\end{tabular}

\subsection{Biographic data}

The participation rate of males was $28.3 \%$ whereas that of females was $70.2 \%$. This may be attributed to the fact that most females occupy junior positions whilst males occupy senior positions in universities. This implies that gender equity is still to be addressed at both junior and senior positions within universities as South Africa strives for equity within all the spheres of the organisational structures. A significant percentage of the respondents (62.4\%) seem to have been with the institution for more than three years while $33.6 \%$ of them appear to have been at the institution for a period of less than three years. The majority of the respondents (36.3\%) have post-graduate degrees, followed by $19.2 \%$ with degrees, 
$18.2 \%$ with diplomas, $13.7 \%$ with a matriculation certificate and $8.2 \%$ with a professional certificate. The majority of three strata of the participants who have gained a higher level qualification places these groups in an opportune position to receive and more accurately interpret both employee involvement and lack of involvement.

The majority of respondents were administrative staff, $40.7 \%$, followed by $35.1 \%$ who were academic staff and $20.5 \%$ service workers, a term which covers employees working mostly in cleaning, gardening and projects services at the institution. The lower the job level, the higher the seniority and the level of decision-making which respondents exercise in their jobs. The majority of respondents are at job level 15 and below (19.3\%), followed by job level $8(13.4 \%)$, job level 11(10.2\%), job level 10 (9.8\%), job level 9 (9.5\%), job level 14 (8.3\%), job level 7 (7.6\%), job level 12 (7.1\%) and lastly job level 13 (6.1\%). This high percentage of respondents at the lower job level, from job level 8 downwards, indicates that these respondents are well positioned to adjudicate the level of employee involvement in decision-making as they are the ones in the lowest echelons of decision-making within the institutions and they are at the operational level where these decisions must be implemented.

\subsection{Decision-making dimensions}

Data collected was divided into four identified dimensions measuring employees' perceptions of their involvement in decision-making, namely power, information, knowledge and rewards. For the purpose of analysis, the responses pertaining to "agree" and "strongly agree" were combined to denote agree, while those for "disagree" and "strongly disagree" were combined to denote disagree (Welman and Kruger 2000:103).

\subsubsection{Power}

Questions on this dimension sought to discover the extent to which employees are empowered to become involved in decision-making in their daily operations. This includes numerous types of decisions to be made in the institution, from institutional strategy decisions to day to day operational decisions. Any form of decision-making that is made within the institution, but outside the top management team, could be argued as a form of participative decision-making.

Most employees agree that they have a say in how their work is structured (60.2\%) and also have the opportunity to do what they do best in their job (61.7\%). A number of employees (39.8\%) consider that they have no say in how their work is structured while $38.3 \%$ disagree with the statement that they have the opportunity to do what they do best in their job. Most employees (59.3\%) disagree with the statement that their superiors do care about them as individuals, whilst (40.7\%) agree with it.

A majority of these employees disagree with the statements that their opinions count (57.1\%),they contribute to the strategic vision and mission of the institution (67.5\%), they are given a chance to contribute to the quality of the service the institution is offering (63.2\%) and they are given room to participate in decisions that affect their job (64.9\%). A significant number of these employees concur with the statements that their opinions count (42.9\%) that they contribute to the strategic vision and mission of the institution (32.4\%), they are given a chance to contribute to the quality of the service the institution is offering (36.8\%) and are given room to participate in decisions that affect their job (35.2\%).

The majority of the employees agree with the statement that they are accountable and responsible for decisions they take in their job (57.6\%) whereas (42.4\%) disagree. With regard to the statement that the institution is creating an environment conducive for the employees to impact on decisions and actions which affect their job, the majority disagree (64.3\%) whilst (35.6\%) of respondents agree.

Just over half of employees (51.5\%) agree that they are part of a team which works for a common goal. However, a significant number (48.5\%) disagree. The majority of the employees disagree (60.9\%) with the statements that their opinions are important and that they give inputs in improving the production process in the institution (59.1\%). A significant number of employees nonetheless agree with the statement that their opinions are important (39.1\%) and that they give inputs in improving production processing the institution (39.9\%).Most employees concur with the statement that they enjoy communicating information and ideas with their colleagues although (32.9\%) disagree.

\subsubsection{Information}

This dimension sought to investigate how many types of shared communications ranging from institutional performance to actual employee output to almost any type of knowledge are transferred. Most employees (59.5\%) disagree with the statements that they receive information regarding matters that will affect them at work, they are informed of any changes 
that will affect their job (59\%), they are making an impact in decisions regarding the dissemination of information in their respective departments (61\%), their inputs in the department meetings are taken into consideration (55.4\%), they are receiving enough information about the institution(61.2\%), they are given an opportunity at work to learn and grow (56.6\%),there is regular information sharing of gains made through employee involvement efforts (67\%),management informs them sufficiently of their activities (63.6\%), there is constant feedback offered to employees who have made suggestions (74.1\%) and they are informed about developments taking place within the institution (62.2\%).

This indicates inadequate information sharing that could negatively affect these employees' performance and be a hindrance in gathering information about them as to how they work, and where training may be necessary, all of which could lead to an increase in effectiveness, teamwork and performance. However, a significant number of employees agree on receiving information regarding incentives that will affect them at work $(40.5 \%)$, being informed of any changes that will affect their job (41\%), making an impact in decisions regarding the dissemination of information in their respective departments (39\%), giving inputs in the department meetings which are taken into consideration (44.6\%),being given enough information about the institution(38.8\%), being accorded an opportunity at work to learn and grow (43.4\%), regular sharing of gains made through employee involvement efforts (33\%),management informing them sufficiently of their activities (36.4\%), constant feedback offered to employees who have made suggestions (25.9\%) and being informed about developments taking place within the institution (37.8\%).

This is indicative of how much effort the institution's management must devote, towards accomplishing a situation where the communication lines are open between the employees and management so as to lead to increased job satisfaction and a positive attitude, not only towards the position of the former but also to the institution itself.

\subsubsection{Knowledge}

This dimension elicited information about the skills, abilities and knowledge of employees. This is important for their involvement in decision-making in that it allows them to engage robustly with issues and the development of new ideas in taking their institution forward. The majority of the employees (70.9\%) agree that they know what is expected of them in their job. This is a positive response and is affirmative for the given institution since it endeavours to instil a culture and environment conductive to employee participation in decision-making. This is because the employees are required to operate in a climate of guidelines, directives, time-frames and goals where there will be no tolerance for individuals who are idling not knowing what to do. This can perhaps be explained by the significant number of these employees (29.1\%) who disagree with this statement.

Most employees disagree (64.1\%) that they have a say in determining the type of training that they should undergo, they are offered regular training to improve their job (68.1\%),they have a clear vision about developments in the organisation (59.2\%) and the organisation provides them with sufficient work related training (63.2\%). This state of affair does not bode well for an institution which hopes to allow or encourage its employees to share or participate in decisionmaking.

Consequently it is incumbent upon this institution to devise the best possible means that will allow employees to acquire the necessary knowledge to partake in effective decision-making processes. It should be a concern for this institution as just over a third of employees (35.9\%) agree with the assertion that they are given a say in determining the type of training that they should undergo, they are offered regular training to improve their job (31.9\%) and the organisation provides them with sufficient work related training (63.2\%), while just over a quarter agree that they have a clear vision about development in the organisation (40.8\%). Employees need to be made aware of the processes, be offered insightful knowledge into the institution's needs and be made to understand the policies of the institution and its overall direction.

\subsubsection{Rewards}

This is a critical component of employee involvement effectiveness, in particular, sharing organisational rewards is crucial because employees obtain more power, information and knowledge, and they expect more when they feel that their participation has made the organisation more effective.

From the data collected in this dimension it is observed that most employees (76.3\%) disagree with the statement that they are given a say in determining how their reward has to be structured, while $73.7 \%$ disagree that they are involved in the development of reward regarding their performance, $61.7 \%$ agree that their job gives them enough recognition, $60.5 \%$ agree that when they do their job they are recognised and lastly 56.5\%agree that they do receive recognition or praise for work well done. This type of environment will heighten conflict and lead to emotional strain on the 
part of employees. Hence, it is suggested that more proactive employee involvement in decision-making regarding the employees' rewards be implemented for them to gain a greater sense of job satisfaction, motivation and institutional loyalty.

A number of employees (23.7\%) agree with the statement that they are given a say in determining how their reward has to be structured, $26.3 \%$ agree that they are involved in the development of reward regarding their performance, 38.3\% agree that their job gives them enough recognition, 39.5\% agree that in case where they do their job they are recognised and lastly $43.5 \%$ concur that they do receive recognition or praise for work well done.

Interestingly $63.6 \%$ of the employees indicated that they are proud of their job, whilst over a third (36.4\%) disagree with the statement that they are proud of their job. An environment and climate of employee involvement could promote a feeling of psychological empowerment as evident from the high number of employees being proud of their job. This may intensify institutional commitment.

\subsection{Comparison of average dimensions for involvement in decision-making of employees}

The frequency and percentage scores were calculated according to the number of responses both from those who agree and those who disagree in each dimension. As regards disagreement with the statements on each dimension, the dimension with the highest score on both frequency and percentage scores is information (f: 254.10; 61.98\%), followed by rewards (f: $249.5 ; 60.85 \%$ ), knowledge (f: $229 ; 56.82 \%$ ) and lastly power (f: $221 ; 53.9 \%$ ).It is notable that an overwhelming number of the respondents disagree while a sizeable number agree with the statements that attempt to elicit the employees' perceptions about their involvement in decision-making dimensions. This supports the major finding that there seems to be a lack of employee involvement in decision-making at this institution.

\subsection{Empirical findings}

There is a notable and overwhelming agreement that there seems to be a lack of employees' involvement in decisionmaking at this institution as illustrated by the majority of the respondents reporting a perception that they are not involved in decision-making in all dimensions employees' could be. It appears that an environment where employees share ideas and becoming innovative is not being created. This kind of environment would not augur well for this institution as this may negatively affect the employees' job satisfaction, motivation level and relationships. It is further noted that effective and high performing organisations have a culture that encourages employee's involvement; hence the latter are more willing to become involved in goal setting, decision-making or problem solving activities, which results in higher employee performance.

Employee involvement encourages the modern style of participatory management, increases satisfaction, raises employee productivity and lowers the employee compensation rates. Furthermore, employee involvement encourages job satisfaction, which increases productivity through bringing about a higher quality of motivation and working capabilities at times of implementation. Human Resource policies that encourage employees' involvement and thereby aim at providing workers with opportunities to acquire the appropriate skills, incentives to expand discretionary efforts and to make an input into decision-making will assist modern organisations to weather the current challenges facing them.

\section{Recommendations}

In order for employee involvement to be optimally effective, the buy-in, support and commitment of both management and employees in an organisation are essential. It is therefore incumbent on the entire organisation to establish meaningful structures that support the rolling out of employee involvement. Willingness to involve employees making decisions must be constantly demonstrated by supervisors and line managers concerned. It is furthermore important to ensure that continuous employee and management training in employee involvement practices is executed for the process to be successful.

Based on the findings of this study reported above, the following recommendations for future research are made:

\subsection{Recommendations for future research}

1. On-going research on the different aspects regarding employee involvement in HEl's be encouraged.

2. A study should be conducted to investigate the impact of the involvement of employees in decision-making to 
avoid such issues as the occurrence of the 2012 unprotected strikes that are ravaging the country.

3. Research could be conducted into the utilisation of participative action research methods, with the aim being to increase employee involvement and conflict resolution in HEls.

4. Future research should also be conducted into the implications of training both management and employees in ensuring successful and meaningful employee involvement strategies.

5. The research study was limited in the sense that it was mainly employees in lower levels and academics within the institution who responded to the survey questionnaire; a further detailed research on the management's perceptions of employee's involvement in decision-making in organisations could bring different insights.

6. Further research is suggested in measuring the extent of employee involvement in different organisational layers as well as investigating whether different involvement dimensions can be applied in each layer or not. This will attempt to illuminate workers' perceptions of the extent to which they are involved and look beyond formal involvement structures to more informal manifestations of employee involvement (Marchington \& Suter, 2012: 289).

\subsection{Recommendations for employee involvement within HEl's}

1. Employees need to be fully trained to participate fully in any decision-making structures so as to have skills and competencies required for effective employee involvement.

2. Employers should be willing and prepared to accept high level decision-making by workers within the institution, involvement should not be restricted to low and middle level involvement.

3. Employee involvement has to be encouraged throughout the entire institution in order to be competitive in the $21 s t$ century. Involvement is encouraged to expand, through the inclusion of more workers and involve them in broader array of issues if it is to meet the expectations and address the vital concerns of all employees.

4. Continuous seminars and workshops concerning labour related matters such as employee involvement, participation and engagement be held in an attempt to forge more compatible views, values and perceptions among all stakeholders within the institution.

5. Greater effectiveness in achieving higher involvement of employees in decision- making could be attained by providing HEl employees with the following dimensions: power, information, knowledge and rewards. Employers should be careful to ensure that talk about employee involvement in decision-making should not replace action.

\section{Limitations of the Study}

Firstly, the research is undertaken within the context of an institution of higher learning in South Africa, with particular reference to how employees perceive their involvement in decision making process. Any findings made in this dissertation will in turn be limited to the 'snapshot' of events which may not be typical of any one university. Further, the findings are limited to observations in a particular University of Technology and are not generalisable to other sectors.

The study was limited by the instrument used. While the return rate was good, it was noted that the responses could have been a mere reaction to a request to complete the questionnaire. It does seem as if many respondents did not really apply their minds to the questionnaire items. This could perhaps be the reason for high percentages "agree" response to a majority of the items. A combination of the various qualitative and quantitative research methods could perhaps have addressed this limitation.

\section{Summary}

This article presented the overall synopsis of the entire study with regards to the summary, findings, recommendations, limitations and recommendations for further research.

The study explored the nature of employees' involvement in decision- making and strategies of employee involvement in the workplace. Significant findings were made in this respect. Recommendations where thus made on the basis of findings, both in the literature review and empirical study.

This research therefore brings to the fore the concept of employees: involvement in HEls and sets the tone for further research in this regard. 


\section{References}

Ahmed. A. (2013). Employee engagement level in management colleges: Singaporean Journal of business economics and management studies. 1(7), 2013.

Ang, J. (2002). An eclectic review of the multidimensional perspectives of employee involvement. The TQM Magazine, 14(3): 192-200.

Bhatti, K.K. \& Qureshi, T.M. (2007). Impact of employee participation on job satisfaction, employee commitment and employee productivity. International Review of Business Research Papers: 3(2), 54-68.

Boyce, J. (2002). Marketing research in practice. Milan: McGraw-Hill.

Cummings, T.G., \& Worley, C.G. (2008). Organisation development and change. $8^{\text {th }}$ ed. Cincinnati: Southern-Western college publishing.

DeVos, A.S., Strydom, H., Fouche, C.B. \&Delport, C.S.L. (2002). Research at grassroots: for the social sciences and human service professions. Pretoria: Van Schaik.

Du Pre, R.H. (2005). Message from the Acting Vice-Chancellor.Vanderbijpark: Vaal University Press.

Echols, A.E. \& Neck, C.P. (1998). The impact of behaviours and structures on corporate entrepreneurial success.Journal of Managerial Psychology, 13 (1/2):38-46.

Edwards, P. (2007). Justice in the workplace: Why it is important and why a new public policy initiative is needed. Provocation Series, 2 (3):3-45.

Frost, A.C. (2000). Union involvement in workplace decision-making: Implications for union democracy. Journal of Labour Research, 21 (2): $265-287$.

Guthrie, J.P. (2001). High-involvement work practices, turnover, and productivity: Evidence from New Zealand. Academy of Management Journal, 44(1):180-190

Grobler, P., Warnich, S., Carrell, M.R., Elbert, N.F. \& Hatfield, R.D. (2011). Human Resources Management in South Africa.4th ed. London: Thompson.

Hanna, M.D., Newman, W.F. \& Johnson, P. (2000). Linking operations and environmental improvement through employee involvement. International Journal of Operations and Production Management, 20 (2): 148 - 165.

Heathfield, S.M. (2011).Employee retention as a challenge in leather industry.Global Journal of Human and Social Science,11 (2): I -13

Heller, F., Pusic, E., Strauss, G. \& Wilpert,B. (1998). Organisational participation: myth and reality. USA: Oxford University Press

Hellriegel, D., Jackson, S.E. \& Slocum, J. (2005). Management: South African edition. Cape Town: Oxford.

Jackson, .T.B., \& Rothmann, S. (2005). Work-related well-being of educators in the district of the North West Province. Perspectives in Education. 23, 107-122.

Jones, D.C. Kalmi, P. \& Kauhanen, A. (2010).How does employee-involvement stack up? The effects of human resource management policies on performance in a retail firm. Industrial Relations: A journal of economy and society, 49 (1): 1-21.

Jones, D.C. \& Kato, T. (2005). The effects of employee involvement on firm performance: evidence from an economic case study. William Davidson Institute.

Knudsen, H. (1995). Employee participation in Europe. London: Sage Publishers

Lin, W.B. (2006). The exploration of employee involvement model, Expert Systems with Applications, 31:69-82.

Macey, W.H. \& Schneider, B. (2008). The meaning of employee engagement. Industrial and Organisational Psychology, 1:3-30.

Marchington, M. \& Suter. J. (2012). Where informality really matters: Patterns of employee involvement and participation (EIP) in a nonunion firm. Industrial Relations, 52 (1): 284-313.

Marsden, D. (2007). Individual employee voice and performance management in public services. International journal of Human Resources Management, 18(7):1263-1278.

Mchunu, M. (2010). Impact of employee participation in decision making at Engen. M.B.A Dissertation. Durban: University of Kwazulu-Natal.

Noah, Y. (2008). A study of worker participation in management decision making within selected establishments in Lagos, Nigeria. Journal of Social Science, 17 (1): 31-39.

Pendleton, A., \& Robinson, A. (2010). Employee stock ownership, involvement and productivity: An interaction-based approach. Industrial and Labour Relation Review, 64(1):3-29

Pfeffer, J. (1998). The Human Equation: Building profits by putting people first. Boston Mass: Harvard Business School Press.

Pityana, N.B.(2004). Higher Education In South Africa: future perspective. Keynote address at Venter/Altron Literary awards 2003; Wednesday 7 April 2004, Westcliff Hotel, Johannesburg.

Schultz, K., van der Walt, H.\&Bezuidenhout, A. (2011). Creating a culture for employee engagement: ten valuable keys: human resources, Management today, 29 (2): 52-53.

Stoner, J.A., Freeman, R.E., \& Gilbert, D.A. (1995). Management. $6^{\text {th }}$ Ed. Prentice Hall: New Jersey.

Vance, R.J. (2006).Employee engagement and commitment:A guide to understanding, measuring and increasing engagement in your organisation. Alexandria, V.A: Society of Human Resources Management.

Vockel,E.L. \& Asher,J.W. (1995). Educational research. Engelwood Cliffs, NJ: Prentice-Hall.

Wanberg, C. \& Banas. J. (2000). Predictors and outcomes of openness to changes in a reorganising workplace, Journal of Applied Psychology, 1: 132-142.

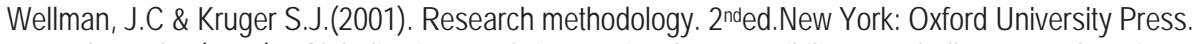

Wessels, J.S. (2002). Globalisation and international compatibility: a challenge to learning within the context of application. SAJHE/SATHO, 16(1): 189-194.

William, H.M.(2008). The meaning of employee engagement. Industries and organisational psychology,20(1):3-30

Wood, S. (1999). Human resource management and performance. International Journal of Management Reviews,51(4):367-414. 